\title{
Molecular Analysis of Carbapenem-Resistant Pseudomonas aeruginosa Isolated from Patients Hospitalized in Daejeon between 2008 and 2014 Years
}

Hye Hyun Cho

Department of Biomedical Laboratory Science, Daejeon Institute of Science and Technology, Daejeon, Korea

\section{대전지역의입원환자에서분리된 Carbapenem 내성 Pseudomonas aeruginosa의 분자역학조사(2008년에서 2014년까지)}

조혜현

대전과학기술대학교 임상병리과

\begin{abstract}
The emergence of carbapenem resistance among Pseudomonas aeruginosa has become an increasing problem worldwide. In particular, metallo- $\beta$-lactamases (MBLs) are responsible for the high-level resistance to carbapenem. Sequence type 235 (ST235) has been found internationally in a multidrug-resistant clone and is involved in the dissemination of genes encoding IMP-6 and $\mathrm{VIM}-2$. This study examined the prevalence of MBLs and the epidemiological relationship in carbapenem-resistant $P$. aeruginosa (CRPA) isolates obtained from a tertiary hospital in Daejeon, Korea, between March 2008 and June 2014. The antimicrobial susceptibilities were determined using the disk-diffusion method and PCR and DNA sequencing were used to identify the MBL genes. In addition, an epidemiological relationship was investigated by multilocus sequence typing (MLST). Among the 110 CRPA isolates, 32 isolates (29.1\%) were MBL-producers; the major type was IMP-6 (29 isolates, 90.6\%). VIM-2 was identified in 3 isolates (9.4\%) of ST357. IMP-6-producing isolates were multidrug-resistant (MDR) and belonged to ST235. ST235 (55 isolates, $50.0 \%$ ) was the clone most frequently detected and has gradually emerged during a seven-year period. To prevent the spread of MDR ST235 P. aeruginosa isolates, the current widespread use of carbapenems needs to be curtailed, and novel continuous monitoring strategies should be developed as soon as possible.
\end{abstract}

Key words: CRPA, IMP-6, Multidrug-resistant, ST235, VIM-2

This is an Open Access article distributed under the terms of the Creative Commons Attribution Non-Commercial License (http://creativecommons.org/licenses/by-nc/4.0) which permits unrestricted non-commercial use, distribution, and reproduction in any medium, provided the original work is properly cited.

Copyright $\odot 2018$ The Korean Society for Clinical Laboratory Science. All rights reserved.
Corresponding author: Hye Hyun Cho Department of Biomedical Laboratory Science, Daejeon Institute of Science and Technology, 100 Hyechon-ro, Seo-gu, Daejeon 35408 Korea

Tel: 82-42-580-6341

Fax: 82-42-580-6301

E-mail: airplane1102@hanmail.net

Received: August 21, 2018

Revised $1^{\text {st: }}$ September 3, 2018

Revised $2^{\text {nd }}:$ September 10, 2018

Accepted: September 10, 2018

\section{서 론}

Pseudomonas aeruginosa는 광범위한 기회감염과 원내감 염을 일으키는 중요한 원인균이다. 이러한 P. aeruginosa의 항 균제에 대한 내재된 높은 내성과다제내성(multidrug-resistance, $\mathrm{MDR}$ 으로 발달하는 능력은 P. aeruginosa 감염의 치료에 심각
한 문제가 되고 있다. 최근, P. aeruginosa 감염과 관련된 사망 율이 증가하고 있으며, 다제내성 P. aeruginosa에 의한 원내감 염이 전 세계적으로 증가하고 있는 실정이다[1-3].

Carbapenem은 다제내성 P. aeruginosa 감염에 대한 효과 적인 치료제로 사용되고 있으나, 최근에는 이러한 다제내성 $P$. aeruginosa가 carbapenem에 높은 내성으로 발달하여 그에 대 
한 심각성이 전 세계적으로 보고되고 있다[4-6]. 특히 우리나라 에서는 carbapenem의 높은 사용율로 인해 이러한 문제가 더 욱 심각하게 보고되고 있다[7, 8]. 전국병원감염감시체계(Korean Nosocomial Infections Surveillance System, KONIS)에 따르 면, 국내병원에서 분리된 P. aeruginosa를 대상으로 carbapenem 에 속하는 항균제인 imipenem의 내성율을 조사한 결과, 2006 년 43.5\%에서 2013년 50\%로, 6.5\%가 증가하였다. 이러한 내 성율의 증가는 metallo- $\beta$-lactamase (MBL)와 중요하게 관련 되어 있다[9]. 또한, 최근 연구에서도 MBL 유전자 중 IMP와 Verona integron-encoded metallo- $\beta$-lactamase (VIM) 유 전자가 P. aeruginosa에서 가장 우세하게 확산되고 있는 유전 자로 보고되고 있다[2, 6].

전 세계적으로 $\mathrm{MBL}$ 을 생성하는 P. aeruginosa에서 우세하 게 알려져 있는 두 개의 clonal complex는 CC111과 CC235이 다. 특히, CC235는 유럽에서 분리된 VIM을 생성하는 $P$. aeruginosa와 일본, 브라질, 싱가포르에서 분리된 IMP와 São Paulo metallo- $B$-lactamas (SPM-1)을 생성하는 P. aeruginosa 를 통해, MBL 유전자 확산의 주요 원인으로 알려져 있다 [10-12].

국내에서도 P. aeruginosa를 대상으로 carbapenem 내성과 관련된 연구가 보고되고 있으나, 특정지역에서 장기간 동안의 내성 관련 연구와 역학조사는 드문 실정이다. 이에 본 연구에서 는 7년 동안 대전지역의 3차 병원에서 분리된 carbapenem 내 성 P. aeruginosa를 대상으로 $\mathrm{MBL}$ 유전자를 분석하고, 이에 대 한 역학관계를 조사하고자 한다.

\section{재료 및 방법}

\section{1. 균주의 수집과 동정}

본 연구는 2008년 3월부터 2014년 6월까지 대전지역의 3차 병원에서 분리된 P. aeruginosa 중 carbapenem에 내성을 보 인 110 균주를 대상으로 하였다. 이 중 동일 환자에서 반복 분리 된 균주는 수집대상에서 제외하였다. 임상검체로부터 분리 배 양된 균주는 Vitek 2 automated ID system (BioMerieux, Hazelwood, MO, USA)을 이용하여 동정하였고, carbapenem 내성 P. aeruginosa는 imipenem과 meropenem에 내성인 균 주로 선별하였다.

\section{2. 항균제 감수성 검사}

Clinical and laboratory standards institute (CLSI) 지침에 따라, amikacin, gentamicin, imipenem, meropenem 및 ciprofloxacin (BBL, Cockeysville, MI, USA)에 대한 감수성 검 사는 Mueller-Hinton 한천배지 (Difco, Cockeysville, MD, $\mathrm{USA}$ )를 사용하여 디스크 확산법으로 확인하였다[13]. 정도관 리를 위해 Escherichia coli ATCC 25922와 Pseudomonas aeruginosa ATCC 27853을 동시에 시험하여 허용범위 내에 있 는지 확인하였다.

Magiorakos 등[14]의 연구를 참고하여, aminoglycosides, carbapenems 및 fluoroquinolones 계열에 내성을 보인 균주 를 다제내성 P. aeruginosa로 하였다.

\section{Multilocus sequencing typing (MLST) 분석}

MLST는 P. aeruginosa MLST database website (http:// pubmlst.org/paeruginosa/)에 설명된 방법에 따라 분석하였 다. 먼저, 대상 균주는 brain heart infusion broth (Difco)에 접 종하여 $37^{\circ} \mathrm{C}$ 에서 24 시간 배양한 후, Genomic DNA Prep Kit (Solgent, Daejeon, Korea)를 사용하여 DNA를 추출하였다. DNA 추출액(5 $\mu \mathrm{L}), 10 \mathrm{x}$ Taq buffer $(2.5 \mu \mathrm{L}), 10 \mathrm{mM}$ dNTP mix $(0.5 \mu \mathrm{L})$, primer 각 $10 \mathrm{pmol}, 0.7 \mathrm{U}$ Taq DNA polymerase (Solgent) 및 증류수를 혼합하여 총 부피 $25 \mu \mathrm{L}$ 의 반응용액을 만들었다. 7개의 housekeeping gene ( $a C S A, a r o E$, guaA, mutL, nuoD, ppsA, trpE)은 Gene Amp PCR System 9600 (Perkin-Elmer, Norwalk, CT, USA)을 사용하여 $96^{\circ} \mathrm{C}$ 에 서 1 분간 반응시킨 후, $96^{\circ} \mathrm{C}$ 에서 1 분, $55^{\circ} \mathrm{C}$ 에서 1 분, $72^{\circ} \mathrm{C}$ 에 서 1 분으로 30 회 증폭 반응시키고, $72^{\circ} \mathrm{C}$ 에서 10 분간 연장 반응 시켰다. 각각의 PCR 반응산물은 ethidium bromide가 포함된 $1 \%$ agarose gel에서 30 분간 전기영동하여 밴드를 확인하였다. 증폭산물은 PCR purification Kit (Solgent)로 분리한 후, BigDye Terminator cycle sequencing kit (PE Applied Biosystems, Foster City, CA, USA)와 ABI PRISM 3730xl DNA analyzer (PE Applied Biosystems)를 이용하여 염기서열 을 분석하였다. 7 개의 housekeeping gene에 대한 각각의 염기 서열 분석 결과는 MLST database에 입력하여 allelic number 와 sequence type (ST)를 확인하였다.

\section{4. $\mathrm{MBL}$ 유전자의 검출}

$\mathrm{MBL}$ 유전자를 확인하기 위해, MLST 분석과 동일한 방법으 로 DNA 추출액 $(5 \mu \mathrm{L}), 10 \mathrm{x}$ Taq buffer $(2.5 \mu \mathrm{L}), 10 \mathrm{mM}$ dNTP mix $(0.5 \mu \mathrm{L})$, primer 각 $10 \mathrm{pmol}, 0.7 \mathrm{U}$ Taq DNA polymerase (Solgent) 및 증류수를 혼합하여 총 부피 $25 \mu \mathrm{L}$ 의 반응용액을 만들었다.

PCR 과정은 Poirel 등[15]과 Pollini 등[16]의 연구에서 사용 
된 primer와 반응조건을 참고하여 진행하였다(Table 1). 생성 된 반응산물은 ethidium bromide가 포함된 $1 \%$ agarose gel에

Table 1. Oligonucleotides used as primers for amplification and sequencing in this study

\begin{tabular}{|c|c|c|c|}
\hline $\begin{array}{l}\text { Gene } \\
\text { target }\end{array}$ & Primer sequence (5'-3') & $\begin{array}{l}\text { Product } \\
\text { size (bp) }\end{array}$ & References \\
\hline blaimp & $\begin{array}{l}\text { GGAATAGAGTGGCTTAAYTCTC } \\
\text { GGTTTAAYAAAACAACCACC }\end{array}$ & 232 & [15] \\
\hline blavım & $\begin{array}{l}\text { GATGGTGTTTGGTCGCATA } \\
\text { CGAATGCGCAGCACCAG }\end{array}$ & 390 & [15] \\
\hline blágIM & $\begin{array}{l}\text { TCGACACACCTTGGTCTGAA } \\
\text { AACTTCCAACTTTGCCATGC }\end{array}$ & 477 & [15] \\
\hline blaspm & $\begin{array}{l}\text { AAAATCTGGGTACGCAAACG } \\
\text { ACATTATCCGCTGGAACAGG }\end{array}$ & 271 & [15] \\
\hline blasım & $\begin{array}{l}\text { TACAAGGGATTCGGCATCG } \\
\text { TAATGGCCTGTTCCCATGTG }\end{array}$ & 570 & [15] \\
\hline blanDM & $\begin{array}{l}\text { GGTTTGGCGATCTGGTTTTC } \\
\text { CGGAATGGCTCATCACGATC }\end{array}$ & 621 & [15] \\
\hline bla & $\begin{array}{l}\text { CTGAAGGTGTACGGAAACAC } \\
\text { GTTCGGCCACCTCGAATTG }\end{array}$ & 322 & [15] \\
\hline bladı & $\begin{array}{l}\text { GCTTGTCTTCGCTTGCTAACG } \\
\text { CGTTCGGCTGGATTGATTTG }\end{array}$ & 699 & [15] \\
\hline bla $\mathrm{FIM}$ & $\begin{array}{l}\text { GAAGCACATGGAAAACTGGG } \\
\text { GATGGGCGAATGAGACAGC }\end{array}$ & 435 & [16] \\
\hline
\end{tabular}

서 30분간 전기영동을 하였고, 밴드를 확인한 후 앞서 진행한 동 일한 방법으로 염기서열을 분석하였다.

\section{결 과}

\section{Carbapenem 내성 P. aeruginosa의 MLST 분석}

110균주의 carbapenem 내성 P. aeruginosa를 대상으로 MLST를 시행한 결과, 총 23개의 ST를 확인하였다(Table 2). 23 개의 ST 중 가장 흔한 유형은 ST235였고, 110 균주의 55균주 (50.0\%)에서 확인되었다. 그 다음으로 ST357이 12균주(10.9\%), ST245가 8균주(7.3\%), ST244가 6균주(5.5\%), ST654가 5균주 (4.6\%)에서 확인되었으며, ST111과 ST257은 각각 3균주 (2.7\%), ST139와 ST274는 각각 2균주(1.8\%)에서 확인되었다. 나머지 14개의 ST (ST155, ST179, ST195, ST260, ST267, ST313, ST589, ST612, ST645, ST708, ST1062, ST1154, ST1455, ST1663)는 각각 1균주(0.9\%)에서 확인되었다.

연도별 분포한 ST의 유형을 살펴보면, 2012년에는 총 23개 의 ST 중 12 개의 ST가 확인되어 가장 다양한 분포를 보였으며, 2008년과 2010년에는 각각 6개의 ST가 분포하였고, 2009년 과 2013년에는 각각 5개의 ST가, 2011년과 2014년에는 각각

Table 2. MLST analysis of 110 carbapenem-resistant Pseudomonas aeruginosa

\begin{tabular}{|c|c|c|c|c|c|c|c|c|}
\hline \multirow{2}{*}{ ST } & \multicolumn{7}{|c|}{ Allelic profile } & \multirow{2}{*}{ No. of isolates (\% } \\
\hline & $\operatorname{acs} A$ & $\operatorname{aroE}$ & guaA & mutL & nuoD & ppsA & $\operatorname{trpE}$ & \\
\hline 235 & 38 & 11 & 3 & 13 & 1 & 2 & 4 & $55(50.0 \%)$ \\
\hline 357 & 2 & 4 & 5 & 3 & 1 & 6 & 11 & $12(10.9 \%)$ \\
\hline 245 & 39 & 6 & 12 & 11 & 3 & 15 & 2 & $8(7.3 \%)$ \\
\hline 244 & 17 & 5 & 12 & 3 & 14 & 4 & 7 & $6(5.5 \%)$ \\
\hline 654 & 17 & 5 & 26 & 3 & 4 & 4 & 26 & $5(4.5 \%)$ \\
\hline 111 & 17 & 5 & 5 & 4 & 4 & 4 & 3 & $3(2.7 \%)$ \\
\hline 257 & 35 & 24 & 36 & 11 & 4 & 15 & 14 & $3(2.7 \%)$ \\
\hline 139 & 35 & 5 & 36 & 11 & 4 & 42 & 7 & $2(1.8 \%)$ \\
\hline 274 & 23 & 5 & 11 & 7 & 1 & 12 & 7 & $2(1.8 \%)$ \\
\hline 155 & 28 & 5 & 36 & 3 & 3 & 13 & 7 & $1(0.9 \%)$ \\
\hline 179 & 36 & 27 & 28 & 3 & 4 & 13 & 7 & $1(0.9 \%)$ \\
\hline 195 & 89 & 30 & 64 & 26 & 48 & 24 & 32 & 1 (0.9\%) \\
\hline 260 & 14 & 5 & 10 & 7 & 4 & 13 & 7 & $1(0.9 \%)$ \\
\hline 267 & 19 & 5 & 12 & 11 & 11 & 4 & 14 & $1(0.9 \%)$ \\
\hline 313 & 47 & 8 & 7 & 6 & 8 & 11 & 40 & $1(0.9 \%)$ \\
\hline 589 & 15 & 5 & 11 & 3 & 4 & 12 & 7 & $1(0.9 \%)$ \\
\hline 612 & 28 & 5 & 58 & 11 & 4 & 15 & 44 & $1(0.9 \%)$ \\
\hline 645 & 6 & 5 & 5 & 3 & 3 & 13 & 1 & $1(0.9 \%)$ \\
\hline 708 & 11 & 3 & 11 & 3 & 1 & 4 & 60 & $1(0.9 \%)$ \\
\hline 1062 & 22 & 5 & 91 & 33 & 4 & 4 & 1 & $1(0.9 \%)$ \\
\hline 1154 & 1 & 101 & 11 & 1 & 1 & 40 & 7 & $1(0.9 \%)$ \\
\hline 1455 & 15 & 5 & 11 & 3 & 58 & 42 & 9 & $1(0.9 \%)$ \\
\hline 1663 & 17 & 18 & 17 & 5 & 4 & 4 & 9 & $1(0.9 \%)$ \\
\hline
\end{tabular}

Abbreviations: MLST, multilocus sequence typing; ST, sequence type. 
4개의 ST가 분포하였다(Table 3). 2008년부터 2014년까지 7 년 동안 지속적으로 확인된 ST 유형은 ST235였고, 2008년 62.5\%, 2009년 38.9\%, 2010년 53.3\%, 2011년 60.0\%, 2012 년 18.2\%, 2013년 45.5\%, 2014년 83.3\%로, 연도별 확인된 ST 중 가장 높은 비율로 분포하였다.

또한, 임상검체의 종류에 따라 110 균주를 분리한 결과, 60 균

Table 3. Prevalence of ST, based on year in 110 CRPA isolates collected during a seven-year period

\begin{tabular}{|c|c|c|c|}
\hline Year & ST & $\begin{array}{l}\text { No. of } \\
\text { isolates (\%) }\end{array}$ & Specimen (N) \\
\hline \multirow[t]{6}{*}{2008} & 235 & $10(62.5)$ & $\begin{array}{c}\text { sputum (4), urine (4), bronchial } \\
\text { aspiration (2) }\end{array}$ \\
\hline & 357 & $2(12.5)$ & sputum (2) \\
\hline & 244 & $1(6.3)$ & sputum (1) \\
\hline & 260 & $1(6.3)$ & sputum (1) \\
\hline & 313 & $1(6.3)$ & sputum (1) \\
\hline & 1154 & $1(6.3)$ & pus (1) \\
\hline \multirow[t]{5}{*}{2009} & 235 & $7(38.9)$ & urine (4), sputum (3) \\
\hline & 357 & $6(33.3)$ & sputum (6) \\
\hline & 139 & $2(11.1)$ & sputum (1), urine (1) \\
\hline & 245 & $2(11.1)$ & sputum (2) \\
\hline & 244 & $1(5.6)$ & sputum $(1)$ \\
\hline \multirow[t]{6}{*}{2010} & 235 & $8(53.3)$ & urine (4), sputum (3), other (1) \\
\hline & 244 & $3(20.0)$ & sputum (2), urine(1) \\
\hline & 155 & $1(6.7)$ & sputum (1) \\
\hline & 245 & $1(6.7)$ & sputum (1) \\
\hline & 274 & $1(6.7)$ & sputum (1) \\
\hline & 612 & $1(6.7)$ & sputum (1) \\
\hline \multirow[t]{4}{*}{2011} & 235 & $6(60.0)$ & wound (3), sputum (2), urine (1) \\
\hline & 245 & $2(20.0)$ & sputum $(2)$ \\
\hline & 179 & $1(10.0)$ & sputum (1) \\
\hline & 267 & $1(10.0)$ & blood (1) \\
\hline \multirow[t]{12}{*}{2012} & 235 & $4(18.2)$ & sputum (2), urine (2) \\
\hline & 111 & $3(13.6)$ & sputum (2), bile (1) \\
\hline & 245 & $3(13.6)$ & sputum (2), urine (1) \\
\hline & 257 & $2(9.1)$ & sputum (1), urine (1) \\
\hline & 357 & $2(9.1)$ & sputum (2) \\
\hline & 654 & $2(9.1)$ & sputum (2) \\
\hline & 195 & $1(4.5)$ & sputum (1) \\
\hline & 274 & $1(4.5)$ & sputum (1) \\
\hline & 589 & $1(4.5)$ & sputum (1) \\
\hline & 645 & $1(4.5)$ & pus (1) \\
\hline & 1455 & $1(4.5)$ & sputum (1) \\
\hline & 1663 & $1(4.5)$ & sputum (1) \\
\hline \multirow[t]{5}{*}{2013} & 235 & $5(45.5)$ & urine $(5)$ \\
\hline & 357 & $2(18.2)$ & sputum (2) \\
\hline & 654 & $2(18.2)$ & sputum (2) \\
\hline & 708 & $1(9.1)$ & bile (1) \\
\hline & 1062 & $1(9.1)$ & blood $(1)$ \\
\hline \multirow[t]{4}{*}{2014} & 235 & $15(83.3)$ & urine (12), blood (2), sputum (1) \\
\hline & 244 & $1(5.6)$ & sputum (1) \\
\hline & 257 & $1(5.6)$ & sputum (1) \\
\hline & 654 & $1(5.6)$ & sputum (1) \\
\hline
\end{tabular}

Abbreviations: See Table 2.
주(54.5\%)가 객담에서 가장 많이 분리되었으며, 그 다음으로 36균주(32.7\%)가 소변에서, 4균주(3.6\%)가 혈액에서, 3균주 (2.7\%)가창상 검체에서 분리되었다. 그 밖에 담즙, 기관지세척 액, 농으로부터 각각 2 균주 $(1.8 \%)$ 가 분리되었으며, 기타 검체 로부터 1균주(0.9\%)가 분리되었다. 연도별 분포한 ST에 따른 임상검체의 종류는 Table 3 과 같이 분리되었다. 110 균주 중 $50 \%$ (55균주)를 차지하고 있는 ST235는 소변에서 32균주 (58.2\%), 객담에서 15 균주(27.3\%), 창상 검체에서 3 균주 (5.5\%), 기관지세척액과 혈액에서 각각 2균주(3.6\%), 기타 검체 에서 1균주(1.8\%)에서 분리되었다.

\section{2. $\mathrm{MBL}$ 유전자의 확인 및 분석}

$\mathrm{MBL}$ 유전자의 검출을 위해 $\mathrm{PCR}$ 과 염기서열을 분석한 결과, 총 110균주의 carbapenem 내성 P. aeruginosa 중 32균주 (29.1\%)에서 확인되었다. 이 중 29균주(90.6\%)는 IMP-6가 확 인되었고, 3 균주(9.4\%)는 VIM-2가 확인되었다. IMP-6가 확인 된 29균주는 모두 ST235였으며, ST235의 총 55균주 중 52.7\% 로 확인되었다. VIM-2가 확인된 3균주는 모두 ST357이었고, ST357의 총 12 균주 중 $25.0 \%$ 로 확인되었다.

\section{3. 항균제 감수성 양상 분석}

총 110균주의 carbapenem 내성 P. aeruginosa를 대상으로 항균제 감수성 검사를 실시한 결과, amikacin에 60균주 (54.5\%), gentamicin에 70균주(63.6\%), ciprofloxacin에 81 균주(73.6\%)가 내성을 보였으며, imipenem과 meropenem에 110 균주(100\%) 모두 내성을 보였다(Table 4). 또한, 총 55균주 의 ST235는 amikacin에 내성인 60균주의 91.8\%로 확인되었 고, gentamicin에 내성인 70균주의 $78.6 \%$ 로 확인되었다. Ciprofloxacin에 내성인 81균주의 67.9\%로 확인되었으며, imipenem과 meropenem에 내성인 110 균주의 각각 50\%로 확인되었다. 이는 총 55균주의 ST235가 모두 다제내성임을 나 타내었다.

\section{고 찰}

최근 P. aeruginosa에서 carbapenem에 대한 내성의 증가 는 우리나라 뿐만 아니라, 전 세계적으로 심각한 문제로 대두되 고 있다. 특히, 우리나라의 경우 대부분의 carbapenem 내성 $P$. aeruginosa가 다제내성으로 보고되고 있어 큰 우려를 낳고 있 다[17, 18].

Carbapenem에 대한 내성 기전은 $\beta$-lactamase 생성, 외막 
Table 4. Antimicrobial susceptibility of $P$. aeruginosa isolates according to ST

\begin{tabular}{|c|c|c|c|c|c|c|c|c|c|c|c|c|c|c|c|c|}
\hline \multirow{2}{*}{ ST } & \multirow{2}{*}{$\begin{array}{l}\text { No. of } \\
\text { isolates }\end{array}$} & \multicolumn{3}{|c|}{ AMK } & \multicolumn{3}{|c|}{ GEN } & \multicolumn{3}{|c|}{ IPM } & \multicolumn{3}{|c|}{ MEM } & \multicolumn{3}{|c|}{ CIP } \\
\hline & & $\mathrm{S}$ & I & $\mathrm{R}$ & $S$ & I & $\mathrm{R}$ & $S$ & I & $\mathrm{R}$ & $S$ & 1 & $\mathrm{R}$ & $S$ & 1 & $\mathrm{R}$ \\
\hline 235 & 55 & 0 & 0 & 55 & 0 & 0 & 55 & 0 & 0 & 55 & 0 & 0 & 55 & 0 & 0 & 55 \\
\hline 357 & 12 & 10 & 0 & 2 & 4 & 4 & 4 & 0 & 0 & 12 & 0 & 0 & 12 & 4 & 0 & 8 \\
\hline 245 & 8 & 6 & 1 & 1 & 4 & 2 & 2 & 0 & 0 & 8 & 0 & 0 & 8 & 0 & 2 & 6 \\
\hline 244 & 6 & 6 & 0 & 0 & 2 & 1 & 3 & 0 & 0 & 6 & 0 & 0 & 6 & 3 & 1 & 2 \\
\hline 654 & 5 & 3 & 0 & 2 & 1 & 0 & 4 & 0 & 0 & 5 & 0 & 0 & 5 & 3 & 0 & 2 \\
\hline 111 & 3 & 3 & 0 & 0 & 0 & 3 & 0 & 0 & 0 & 3 & 0 & 0 & 3 & 0 & 0 & 3 \\
\hline 257 & 3 & 2 & 1 & 0 & 2 & 1 & 0 & 0 & 0 & 3 & 0 & 0 & 3 & 2 & 0 & 1 \\
\hline 139 & 2 & 2 & 0 & 0 & 2 & 0 & 0 & 0 & 0 & 2 & 0 & 0 & 2 & 2 & 0 & 0 \\
\hline 274 & 2 & 2 & 0 & 0 & 2 & 0 & 0 & 0 & 0 & 2 & 0 & 0 & 2 & 2 & 0 & 0 \\
\hline 155 & 1 & 1 & 0 & 0 & 1 & 0 & 0 & 0 & 0 & 1 & 0 & 0 & 1 & 1 & 0 & 0 \\
\hline 179 & 1 & 1 & 0 & 0 & 1 & 0 & 0 & 0 & 0 & 1 & 0 & 0 & 1 & 1 & 0 & 0 \\
\hline 195 & 1 & 1 & 0 & 0 & 1 & 0 & 0 & 0 & 0 & 1 & 0 & 0 & 1 & 0 & 0 & 1 \\
\hline 260 & 1 & 1 & 0 & 0 & 1 & 0 & 0 & 0 & 0 & 1 & 0 & 0 & 1 & 1 & 0 & 0 \\
\hline 267 & 1 & 1 & 0 & 0 & 1 & 0 & 0 & 0 & 0 & 1 & 0 & 0 & 1 & 1 & 0 & 0 \\
\hline 313 & 1 & 1 & 0 & 0 & 0 & 1 & 0 & 0 & 0 & 1 & 0 & 0 & 1 & 1 & 0 & 0 \\
\hline 589 & 1 & 1 & 0 & 0 & 0 & 0 & 1 & 0 & 0 & 1 & 0 & 0 & 1 & 0 & 0 & 1 \\
\hline 612 & 1 & 1 & 0 & 0 & 1 & 0 & 0 & 0 & 0 & 1 & 0 & 0 & 1 & 1 & 0 & 0 \\
\hline 645 & 1 & 1 & 0 & 0 & 1 & 0 & 0 & 0 & 0 & 1 & 0 & 0 & 1 & 1 & 0 & 0 \\
\hline 708 & 1 & 1 & 0 & 0 & 1 & 0 & 0 & 0 & 0 & 1 & 0 & 0 & 1 & 0 & 0 & 1 \\
\hline 1062 & 1 & 1 & 0 & 0 & 1 & 0 & 0 & 0 & 0 & 1 & 0 & 0 & 1 & 1 & 0 & 0 \\
\hline 1154 & 1 & 1 & 0 & 0 & 0 & 0 & 1 & 0 & 0 & 1 & 0 & 0 & 1 & 1 & 0 & 0 \\
\hline 1455 & 1 & 1 & 0 & 0 & 1 & 0 & 0 & 0 & 0 & 1 & 0 & 0 & 1 & 1 & 0 & 0 \\
\hline 1663 & 1 & 1 & 0 & 0 & 1 & 0 & 0 & 0 & 0 & 1 & 0 & 0 & 1 & 0 & 0 & 1 \\
\hline Total & 110 & 48 & 2 & 60 & 28 & 12 & 70 & 0 & 0 & 110 & 0 & 0 & 110 & 26 & 3 & 81 \\
\hline
\end{tabular}

Abbreviations: ST, sequence type; AMK, amikacin; GEN, gentamicin; IPM, imipenem; MEM, meropenem; CIP, ciprofloxacin; S, susceptible; $\mathrm{I}$, intermediate resistant; $\mathrm{R}$, resistant.

단백질의 소실, 유출펌프의 발현으로 알려져 있다[19]. 본 연구 에서는 carbapenem의 내성에 중요한 기전 중 하나인 MBL 유 전자를 확인하였고, 그 결과, 총 110균주의 carbapenem 내성 P. aeruginosa 중 32균주(29.1\%)에서 MBL 유전자가 확인되었 다. 이 중 29균주(90.6\%)는 IMP-6가 확인되었고, 3 균주(9.4\%) 는 VIM-2가 확인되었다. MBL 유전자 중 IMP와 VIM 유전자는 전 세계적으로 가장 확산되어 있는 유전자로 보고되고 있다[20, 21]. 특히 우리나라에서는 IMP-6와 VIM-2 유전자가 우세하게 보고되고 있다[10]. Bae 등[22]의 연구에 의하면, IMP-6와 VIM-2의 생성은 P. aeruginosa에서 carbapenem에 대한 획득 내성의 주요 기전임을 보고하였다. 이와 유사하게 Neyestanaki 등[23]의 연구에서도, 이란에서 분리된 P. aeruginosa의 carbapenem에 대한 주요 내성 기전이 MBLs의 생성임을 보고 하였다.

IMP-6 유전자는 1996년 일본에서 Serratia marcescens $\mathrm{KU} 3838$ 의 plasmid pKU501에서 처음으로 보고되었는데, 이 것은 IMP-1 유전자의 196번째 아미노산인 serine이 glycine으 로 치환된 돌연변이로, meropenem에 증가된 내성을 보였다 [24]. VIM-2 유전자는 1996년 프랑스에서 처음으로 보고되었
으며, imipenem으로 치료한 여성의 혈액배양에서 분리된 $P$. aeruginosa에서 확인되었다[25]. 본 연구에서, IMP-6 유전자 가 확인된 29균주는 모두 ST235로, 다제내성을 나타내었다. 이 전 연구에서 국내의 많은 연구자들 또한 IMP-6를 생성하는 ST235의 출현과 확산에 대해 보고하였다[1, 2, 26, 27]. 최근, Hong 등[26]의 연구에서, IMP-10을 생성하는 ST235와 GES-24를 생성하는 ST244를 국내에서 처음으로 보고함으로 써, carbapenmases의 다양화에 대한 우려를 나타내었다. 우리 나라와 근접한 국가인 중국의 경우, IMP-6를 생성하는 ST244 와ST235가 출현하고 있음을 보고하였고, 일본의 경우, IMP-1, $6,7,10$ 을 생성하는 ST235와 ST357이 확산되고 있음을 보고 하였다[28, 29].

전 세계적으로 다제내성으로 보고되고 있는 ST235는 CC235의 대표적인 클론이다. CC235는 MBLS와 다양한 광범 위 $\beta$-lactamases를 유럽, 아시아, 남아메리카 등에 확산시키고 있는 것으로 알려져 있다 $[11,12]$. 본 연구에서 총 110 균주의 carbapenem 내성 P. aeruginosa 중 55균주(50.0\%)가 다제내 성 ST235로 확인되었으며, 2008년부터 2014년까지 7년 동안 출현하는 것을 확인하였다. 이번 연구에서는 이전 연구를 토대 
로, 동일 지역의 병원에서 분리된 $\mathrm{CRPA}$ 를 대상으로 지속적으 로 추적 관찰하여 ST의 추이를 확인하였으며, 또한, 연도별, 임 상검체의 종류에 따른 ST의 양상을 관찰하였다. ST235는 연도 별 분포에서 가장 높은 비율로 분포하고 있었으며, 임상검체의 종류에 따른 분리빈도를 확인한 결과, 55 균주 중 32 균주 (58.2\%)가 소변에서 분리되어 가장 높은 비율을 보였다. 흥미롭 게도, 연도별 임상검체의 종류에 따른 ST의 양상을 확인한 결 과, 2008년 2012년의 경우, 객담과 소변에서 비슷한 비율로 ST235가 확인된 반면, 2013 2014년의 경우, 1균주를 제외하 고 모두 소변에서 ST235가 확인되었다. 한편, VIM-2 유전자가 확인된 3균주는 모두 ST357이었고, 객담에서 분리되었다. 이 전 많은 연구에 따르면, $\mathrm{MBL}$ 를 생성하는 P. aeruginosa는 ST235, ST357, ST175 및 ST244와 같은 국제적인 클론으로써, 전 세계적으로 확산되고 있음을 보고하였다[30-32]. 이러한 국 제적인 클론들의 확산은 심각한 우려를 낳고 있는데, 이는 본 연 구결과와 같이 다제내성으로 확인되고 있기 때문이다. 최근 국 내에서 아직까지 보고된 바가 없으나, IMP-7이 캐나다, 유럽, 일본, 말레이시아 및 사우디아라비아 등에서 보고되고 있으며, IMP-7을 생성하는 ST357과 ST235가 유럽과 일본 등에서 확 산되고 있어 향후 지속적인 역학조사가 요구된다[29, 33-35].

본 연구에서는 2008년부터 2014년까지, 대전지역의 3차 병 원에서 분리된 carbapenem 내성 P. aeruginosa를 대상으로 역학조사를 실시한 결과, 7년 동안 다제내성 ST235가 확인되었 고, 이 중 IMP-6를 생성하는 ST235는 52.7\%로 확인되어, 국제 적인 클론의 확산이 심각한 실정이다. 다제내성 ST235와 같은 국제적인 클론의 확산을 방지하기 위해, carbapenem의 과도 한 사용을 제한하고, 지속적으로 모니터링하는 전략이 개발되 어야 할 것으로 사료된다.

\section{요 약}

최근 P. aeruginosa의 carbapenem에 대한 내성은 전 세계 적으로 증가하고 있는 실정이다. 특히 metallo- $\beta$-lactamases (MBLs)는 carbapenem의 고도 내성에 관여하고 있는 것으로 보고되고 있다. 한편, Sequence type 235 (ST235)는 다제내성 클론으로써 국제적으로 보고되고 있으며, IMP-6와 VIM-2 유 전자의 확산에도 관여하는 것으로 알려져 있다. 본 연구에서는 2008년 3월부터 2014년 6월까지, 대전지역의 3차 병원에서 분 리된 carbapenem 내성 P. aeruginosa에서 $\mathrm{MBL}$ 유전자를 분 석하고 이에 대한 역학관계를 조사하고자 하였다. 항균제 감수 성 양상은 디스크 확산법으로 확인하였고, $\mathrm{MBL}$ 유전자의 분석
을 위해 PCR과 염기서열분석을 수행하였다. 더불어, 역학 관계 를 조사하기 위해 multilocus sequence typing (MLST)를 실시 하였다. 110 균주의 carbapenem 내성 P. aeruginosa 중, 32균 주(29.1\%)가 MBL를 생성하였고, IMP-6 (29균주, 90.6\%)가주 요하게 확인되었다. VIM-2는 3균주(9.4\%)에서 확인되었으며, 모두 ST357로 확인되었다. IMP-6를 생성하는 P. aeruginosa 는 모두 다제내성을 보였고, ST235로 확인되었다. ST235 (55 균주, $50.0 \%$ )는 가장 높은 비율로 확인된 클론이며 7년 동안 지 속적으로 확인되었다. 이러한 다제내성 ST235의 확산을 방지 하기 위해, carbapenem의 과도한 사용을 제한하고, 지속적으 로 모니터링하는 전략이 개발되어야 할 것으로 사료된다.

\section{Acknowledgements: None}

Conflict of interest: None

Author's information (Position): Cho HH, Professor.

\section{REFERENCES}

1. Yoo JS, Yang JW, Kim HM, Byeon J, Kim HS, Yoo JI, et al. Dissemination of genetically related IMP-6-producing multidrug-resistant Pseudomonas aeruginosa ST235 in South Korea. Int J Antimicrob Agents. 2012;39:300-304. http://doi.org/ 10.1016/j.ijantimicag.2011.11.018.

2. Cho HH, Kwon KC, Sung JY, Koo SH. Prevalence and genetic analysis of multidrug-resistant Pseudomonas aeruginosa ST235 isolated from a hospital in Korea, 2008-2012. Ann Clin Lab Sci. 2013;43:414-419.

3. Wright LL, Turton JF, Livermore DM, Hopkins KL, Woodford N. Dominance of international 'high-risk clones' among metallo- $\beta$-lactamase-producing Pseudomonas aeruginosa in the UK. J Antimicrob Chemother. 2015;70:103-110. http://doi.org/ 10.1093/ $\mathrm{jac} / \mathrm{dku} 339$.

4. Kang CI, Kim SH, Kim HB, Park SW, Choe YJ, Oh MD, et al. Pseudomonas aeruginosa bacteremia: risk factors for mortality and influence of delayed receipt of effective antimicrobial therapy on clinical outcome. Clin Infect Dis. 2003;37:745-751.

5. Livermore DM. Multiple mechanisms of antimicrobial resistance in Pseudomonas aeruginosa: our worst nightmare? Clin Infect Dis. 2002;34:634-640.

6. Rossi Gonçalves I, Dantas RCC, Ferreira ML, Batistão DWDF, Gontijo-Filho PP, Ribas RM. Carbapenem-resistant Pseudomonas aeruginosa: association with virulence genes and biofilm formation. Braz J Microbiol. 2017;48:211-217. http://doi.org/ 10.1016/j.bjm.2016.11.004.

7. Cho HH, Kwon KC, Kim S, Park Y, Koo SH. Association between biofilm formation and antimicrobial resistance in carbapenem-resistant Pseudomonas aeruginosa. Ann Clin Lab Sci. 2018;48:363-368.

8. Lee JH, Lee GS, Lim KH, Eom YB, Kim SM, Kim JB. Patterns of antimicrobial resistance and genotyping of carbapenemase- 
producing imipenem-nonsusceptible Pseudomonas aeruginosa. Korean J Clin Lab Sci. 2010;42:71-80.

9. Choi JY, Kwak YG, Yoo H, Lee SO, Kim HB, Han SH, et al. Trends in the distribution and antimicrobial susceptibility of causative pathogens of device-associated infection in Korean intensive care units from 2006 to 2013: results from the Korean Nosocomial Infections Surveillance System (KONIS). J Hosp Infect. 2016;92:363-371. http://doi.org/10.1016/j.jhin.2015.12. 012.

10. Seok Y, Bae IK, Jeong SH, Kim SH, Lee H, Lee K. Dissemination of IMP-6 metallo- $\beta$-lactamase-producing Pseudomonas aeruginosa sequence type 235 in Korea. J Antimicrob Chemother. 2011;66:2791-2796. http://doi.org/10.1093/jac/dkr381.

11. Samuelsen O, Toleman MA, Sundsfjord A, Rydberg J, Leegaard TM, Walder M, et al. Molecular epidemiology of metallo-beta-lactamase-producing Pseudomonas aeruginosa isolates from Norway and Sweden shows import of international clones and local clonal expansion. Antimicrob Agents Chemother. 2010;54:346-352. http://doi.org/10.1128/AAC. 00824-09.

12. Cholley P, Thouverez M, Hocquet D, van der Mee-Marquet N, Talon D, Bertrand X. Most multidrug-resistant Pseudomonas aeruginosa isolates from hospitals in eastern France belong to a few clonal types. J Clin Microbiol. 2011;49:2578-2583. http:// doi.org/10.1128/JCM.00102-11.

13. Clinical and Laboratory Standards Institute. Performance standards for antimicrobial susceptibility testing; twentieth informational supplement, M100-S20. Wayne, PA: Clinical and Laboratory Standards Institute; 2010.

14. Magiorakos AP, Srinivasan A, Carey RB, Carmeli Y, Falagas ME, Giske CG, et al. Multidrug-resistant, extensively drug-resistant and pandrug-resistant bacteria: an international expert proposal for interim standard definitions for acquired resistance. Clin Microbiol Infect.2012;18:268-281.http://doi.org/10.1111/ j.1469-0691.2011.03570.x.

15. Poirel L, Walsh TR, Cuvillier V, Nordmann P. Multiplex PCR for detection of acquired carbapenemase genes. Diagn Microbiol Infect Dis. 2011;70:119-123. http://doi.org/10.1016/j.diagmicrobio. 2010.12.002.

16. Pollini S, Maradei S, Pecile P, Olivo G, Luzzaro F, Docquier JD, et al. FIM-1, a new acquired metallo- $\beta$-lactamase from a Pseudomonas aeruginosa clinical isolate from Italy. Antimicrob Agents Chemother. 2013;57:410-416. http://doi.org/10.1128/ AAC.01953-12.

17. Lee K, Kim MN, Kim JS, Hong HL, Kang JO, Shin JH, et al. Further increases in carbapenem-, amikacin-, and fluoroquinolone-resistant isolates of Acinetobacterspp. and P. aeruginosa in Korea: KONSAR study 2009. Yonsei Med J. 2011;52:793-802. http://doi.org/10.3349/ymj.2011.52.5.793.

18. Huh K, Kim J, Cho SY, Ha YE, Joo EJ, Kang CI, et al. Continuous increase of the antimicrobial resistance among gram-negative pathogens causing bacteremia: a nationwide surveillance study by the Korean Network for Study on Infectious Diseases (KONSID). Diagn Microbiol Infect Dis. 2013;76:477-482. http:// doi.org/10.1016/j.diagmicrobio.2013.04.014.

19. Lee H, Roh KH, Hong SG, Shin HB, Jeong SH, Song W, et al. In vitro synergistic effects of antimicrobial combinations on $\mathrm{ex}^{-}$ tensively drug-resistant Pseudomonas aeruginosa and Acinetobacter baumannii Isolates. Ann Lab Med. 2016;36:138-144. http:// doi.org/10.3343/alm.2016.36.2.138.

20. Walsh TR, Toleman MA, Poirel L, Nordmann P. Metallo-beta-lactamases: the quiet before the storm? Clin Microbiol Rev. 2005;18:306-325.

21. Queenan AM, Bush K. Carbapenemases: the versatile beta-lactamases. Clin Microbiol Rev. 2007;20:440-458.

22. Bae IK, Suh B, Jeong SH, Wang KK, Kim YR, Yong D, et al. Molecular epidemiology of Pseudomonas aeruginosa clinical isolates from Korea producing $\beta$-lactamases with extendedspectrum activity. Diagn Microbiol Infect Dis. 2014;79:373377. http://doi.org/10.1016/j.diagmicrobio.2014.03.007.

23. Neyestanaki DK, Mirsalehian A, Rezagholizadeh F, Jabalameli F, Taherikalani M, Emaneini M. Determination of extended spectrum beta-lactamases, metallo-beta-lactamases and AmpCbeta-lactamases among carbapenem resistant Pseudomonas aeruginosa isolated from burn patients. Burns. 2014;40:15561561. http://doi.org/10.1016/j.burns.2014.02.010.

24. Yano H, Kuga A, Okamoto R, Kitasato H, Kobayashi T, Inoue M. Plasmid-encoded metallo-beta-lactamase (IMP-6) conferring resistance to carbapenems, especially meropenem. Antimicrob Agents Chemother. 2001;45:1343-1348.

25. Jeong JH, Shin KS, Lee JW, Park EJ, Son SY. Analysis of a novel class 1 integron containing metallo-beta-lactamase gene VIM-2 in Pseudomonas aeruginosa. J Microbiol. 2009;47:753-759. http://doi.org/10.1007/s12275-008-0272-2.

26. Hong JS, Yoon EJ, Lee H, Jeong SH, Lee K. Clonal dissemination of Pseudomonas aeruginosa sequence type 235 isolates carrying bla $a_{\mathrm{IMP}-6}$ and emergence of bla $a_{\mathrm{GES}-24}$ and bla $a_{\mathrm{IMP}-10}$ on novel genomic islands PAGI-15 and -16 in South Korea. Antimicrob Agents Chemother. 2016;60:7216-7223.

27. Wi YM, Choi JY, Lee JY, Kang CI, Chung DR, Peck KR, et al. Emergence of colistin resistance in Pseudomonas aeruginosa ST235 clone in South Korea. Int J Antimicrob Agents. 2017;49: 767-769. http://doi.org/10.1016/j.ijantimicag.2017.01.023.

28. Chen Y, Sun M, Wang M, Lu Y, Yan Z. Dissemination of IMP-6-producing Pseudomonas aeruginosa ST244 in multiple cities in China. Eur J Clin Microbiol Infect Dis. 2014;33: 1181-1187. http://doi.org/10.1007/s10096-014-2063-5.

29. Mano Y, Saga T, Ishii Y, Yoshizumi A, Bonomo RA, Yamaguchi $\mathrm{K}$, et al. Molecular analysis of the integrons of metallo- $\beta$ - lactamase-producing Pseudomonas aeruginosa isolates collected by nationwide surveillance programs across Japan. BMC Microbiol. 2015;15:41. http://doi.org/10.1186/s12866-015-0378-8.

30. Maatallah M, Cheriaa J, Backhrouf A, Iversen A, Grundmann H, Do T, et al. Population structure of Pseudomonas aeruginosa from five mediterranean countries: evidence for frequent recombination and epidemic occurrence of CC235. PLoS One. 2011;6:e25617. http://doi.org/10.1371/journal.pone.0025617.

31. Giske CG, Libisch B, Colinon C, Scoulica E, Pagani L, Füzi M, et al. Establishing clonal relationships between VIM-1-like metallo-beta-lactamase-producing Pseudomonas aeruginosa strains from four European countries by multilocus sequence typing. J Clin Microbiol. 2006;44:4309-4315.

32. Pournaras S, Köck R, Mossialos D, Mellmann A, Sakellaris V, Stathopoulos C, et al. Detection of a phylogenetically distinct 
IMP-type metallo- $\beta$-lactamase, IMP-35, in a CC235 Pseudomonas aeruginosa from the Dutch-German border region (Euregio). J Antimicrob Chemother. 2013;68:1271-1276. http://doi.org/ 10.1093/jac/dkt004.

33. McCarthy KL, Jennison A, Wailan AM, Paterson DL. Draft genome sequence of an IMP-7-producing Pseudomonas aeruginosa bloodstream infection isolate from Australia. Genome Announc. 2017;5. http://doi.org/10.1128/genomeA.00596-17.

34. Hammerum AM, Jakobsen L, Hansen F, Stegger M, Sørensen LA,
Andersen PS, et al. Characterisation of an IMP-7-producing ST357 Pseudomonas aeruginosa isolate detected in Denmark using whole genome sequencing. Int J Antimicrob Agents. 2015; 45:200-201. https://doi.org/10.1016/j.ijantimicag.2014.11.002.

35. Hrabak J, Cervena D, Izdebski R, Duljasz W, Gniadkowski M, Fridrichova M, et al. Regional spread of Pseudomonas aeruginosa ST357 producing IMP-7 metallo-beta-lactamase in central Europe. J Clin Microbiol. 2011;49:474-475. https://doi.org/10.1128/JCM.00684-10. 